\title{
Review on Connections for Original Bamboo Structures
}

\author{
Chaokun Hong ${ }^{1 \mathrm{a}, 2}$, Haitao $\mathrm{Li}^{1 \mathrm{1a} \mathbf{2}^{*}}$, Rodolfo Lorenzo ${ }^{3}$, Gang $\mathrm{Wu}^{1 \mathrm{~b}}$, Ileana Corbi ${ }^{4}$, Ottavia Corbi ${ }^{4}$, \\ Zhenhua Xiong ${ }^{5}$, Dong Yang ${ }^{1 \mathrm{a}, 2}$ and Huizhong Zhang ${ }^{1 \mathrm{a}, 2}$

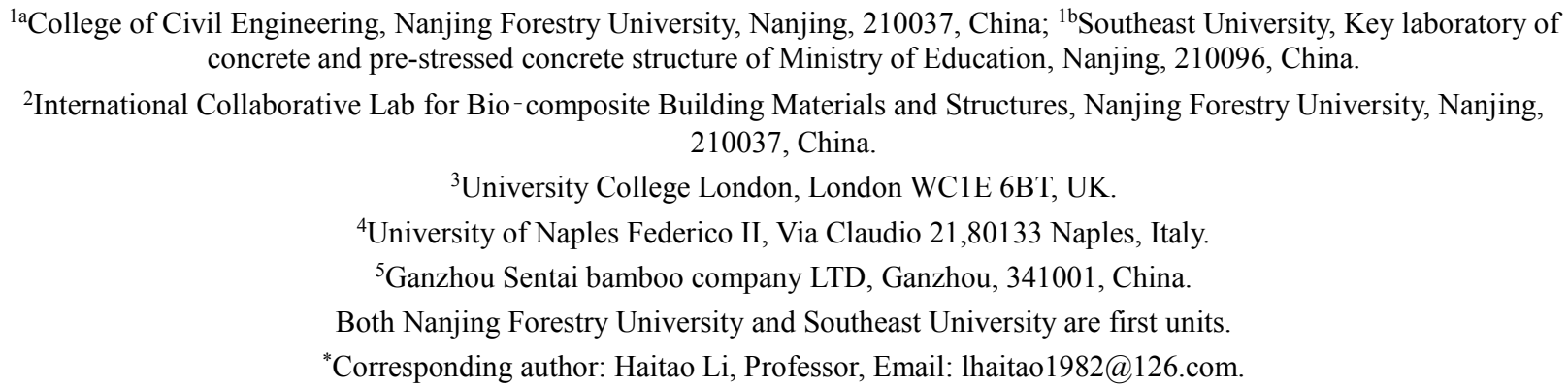

\begin{abstract}
Bamboo is a green construction material in line with sustainable development strategies. The use of raw bamboo in architecture has existed since ancient times. In the long development years of original bamboo buildings, many areas in the world gradually formed unique bamboo buildings, which have become an important local cultural feature. For building structures, joints are the key to ensure structural load transfer. Because of hollow and thin-walled material property of bamboo, the connection in raw bamboo buildings has always been a major difficulty and problem in the application of bamboo, which seriously hinders the development of original bamboo structures. In order to promote the use of raw bamboo, two traditional connection methods in raw bamboo structures are described in this paper firstly, with the advantages and disadvantages of the two methods pointed out. Also, research progress on four categories of raw bamboo building joints is described namely, bolt joints, steel member joints, filler reinforced joints and other types of joints. This work can provide a reference for future research and engineering applications.
\end{abstract}

Keywords: Original bamboo structures; joint; steel members

\section{Introduction}

Similar to wood [1-3], bamboo is a green building material which is environmentally friendly and in line with sustainable development strategies. China is the most important bamboo producing area in the world. It ranks first in the world in terms of species, area, volume and output of bamboo [4]. Bamboo can be used in 3-4 years. It is a fast-growing, non-woody and highly renewable resource with great development value. In recent years, in order to alleviate the high demand for timber resources in China, the bamboo industry has developed rapidly. With natural bamboo as raw material, a series of new products, such as bamboo-woven plywood, bamboo mat plywood, parallel bamboo strand lumber (PBSL) [5-9], laminated bamboo lumber (LBL) [10-14] and Glubam [15] have been developed by using advanced composite and reconstituted technology and are gradually achieving a high level of industrialization.

Raw bamboos are widely distributed in Asia, Africa and Latin America. As an ecological material with good mechanical properties, natural elegance and low price, its application in architecture has existed since ancient times like wood. In China and other countries, people in many areas choose bamboo as the main material for residential construction. The reasons for choosing materials are different between traditional 
dwellings and modern bamboo buildings. The use of bamboo in traditional dwellings such as Dai bamboo buildings (Fig. 1) in China and other kinds of dwellings in South America and Southeast Asia are mainly due to the convenience and economy of materials, while in modern raw bamboo buildings are mainly due to people's pursuit of natural texture as well as the low-carbon environmental protection characteristics.

With the gradual rise of modern bamboo structures, scholars have carried out a lot of research works on bamboo structures [16-28]. However, the popularization and application of bamboo in building structures not only need to understand the basic physical and mechanical properties of bamboo, but also need to master the mechanical properties of joints. The overall performance of building structures, such as strength, stiffness, stability and durability, depends to a large extent on the connection between the components of the structure. The failure of joints endangers the safety performance of the whole structure and may lead to the collapse. Thus, the design of the joint is one of the cores of structural design.

The connection in raw bamboo buildings has always been a major difficulty and problem in the application of bamboo. Raw bamboo is hollow and thin-walled, which makes it confronted with the problems of inconvenient connection and poor reliability in the construction process, which seriously hinders the development of raw bamboo buildings. At present, there are many studies on joints of modern timber structures, while the research on the connection of raw bamboo is relatively few. Therefore, this paper summarizes the forms and research progress of bamboo structural joints in China as well as all over the world, in order to provide a reference for future research and engineering applications.

\section{Traditional Connection Joints in Bamboo Structures}

\subsection{Mortise-Tenon Joints}

Mortise-tenon joint structure is formed by continuous transverse penetration of bamboo beams through multiple columns, and has the characteristics of small material consumption and strong integrity (Fig. 2). The intersection point of the beam and the column is the mortise-tenon joint, which can be regarded as a kind of inheritance and replication of the mortise-tenon joint in timber structure. Bamboo is pulled together and has good ductility and seismic performance [29]. However, the use of mortise-tenon joints need to punch the bamboo beam or column with a hole. Because of the hollow material characteristics of raw bamboo, the cross-section of raw bamboo members is greatly weakened by introducing some drilling holes and therefore, the reliability of joints cannot be guaranteed and it is usually necessary to couple some lashing methods to improve the strength of joints. In addition, the mechanical properties of raw bamboo itself also lead to the limitations of the use of mortise-tenon joints made of bamboo: the mechanical properties of raw bamboo in the perpendicular to grain direction are poor, and the anti-splitting performance is poor as well. During service, the phenomenon of bending, breaking and splitting generally occurs.

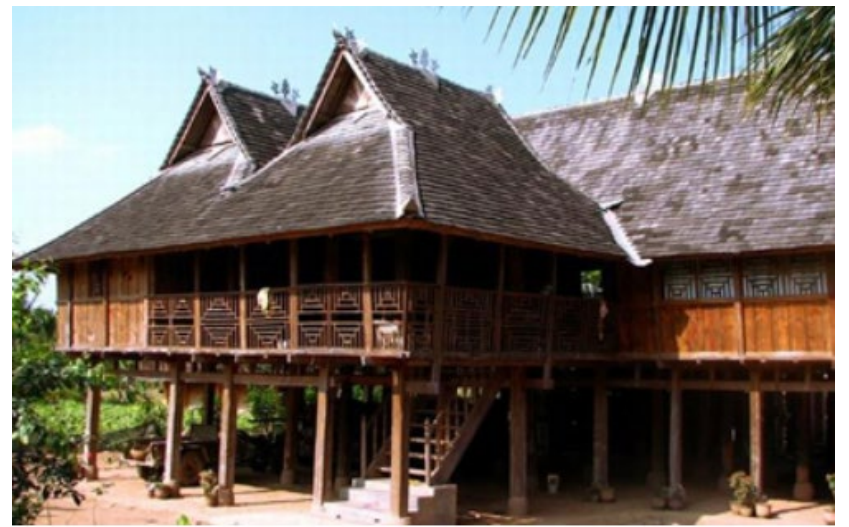

Figure 1: Dai bamboo house [30]

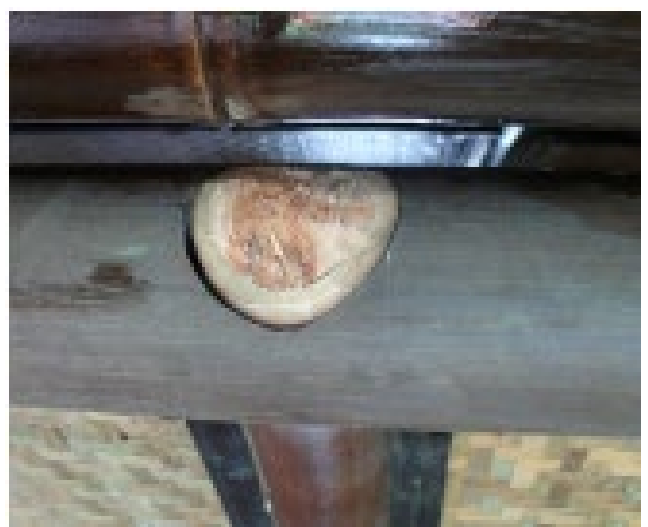

Figure 2: Mortise-tenon joint [31]

\subsection{Lashing Joints}

Lashing is the most common connection method in the past residential buildings (Fig. 3), and has the 
characteristics of good adjustability and low price, but the construction of lashing is low efficient and timeconsuming, and the performance of joints is greatly affected by human operation. Different regions have different selections of rope materials. In the early period, people chose materials mainly because of the convenience of local materials. In some dwellings in warm climate areas such as southern China, palm rope was mostly used to bind bamboo materials (Fig. 4), while in dry climate areas such as northern China, hemp rope was often used. With the development of the times, wires, metal straps, and even polyester plastic ropes and biocomposite bandages [32] are gradually used to enhance the strength of the joints.

Lashing is a reasonable way of connection for bamboo. The flexible connection of bamboo by rope avoids cutting and opening holes in the raw bamboo pole, which weakens the cross-section. Ancient people have summarized a variety of lashing knots through long-term practice and application, which can meet the various connection needs of bamboo. However, due to the flexible connection characteristics of lashing itself, the joint stiffness is insufficient. Once the internal force is not uniform, the rope is prone to sudden breakage. In addition, affected by sunshine, rain, temperature and humidity changes, the rope is often loose, broken and corroded during the using process. It is necessary to replace a new rope in time to ensure normal use. In order to enhance the performance of the joints, the rope is often treated with oil immersion before use to make it more tough and strong, and the strength of the joints can be improved by repeated lashing as well.

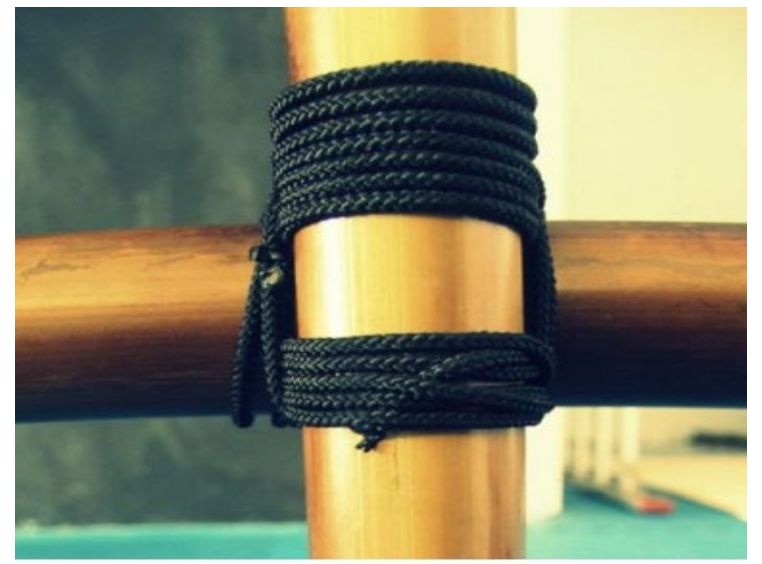

Figure 3: Lashing joint [33]

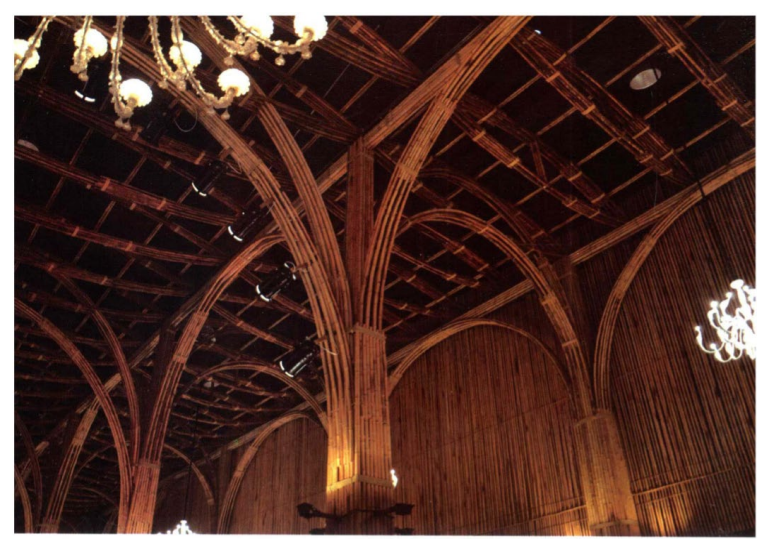

Figure 5: Lashing joint in Vietnam Pavilion [34]

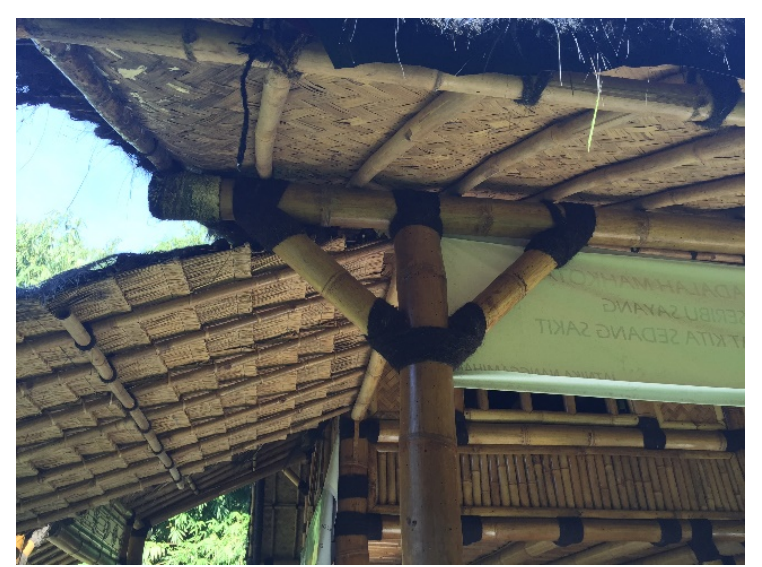

Figure 4: Lashing joint by palm rope

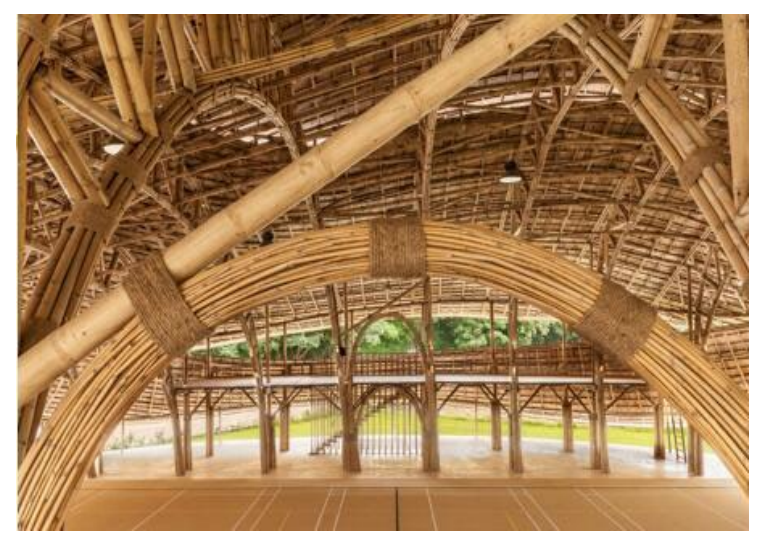

Figure 6: Lashing joint by hemp rope [35]

Although the stiffness of lashing joints is insufficient, they have not been eliminated in the modern raw bamboo buildings. In the 2010 Shanghai World Expo, Vietnamese architect Chongyi Wu used the lashing method to construct the raw bamboo building Vietnam Pavilion. Through ropes, many small 
diameter bamboos were tied together to form various components such as bamboo columns and bamboo arches (Fig. 5). Chiangmai Life Construction, a construction company, built a $782 \mathrm{~m}^{2}$ bamboo stadium in Thailand in 2017. It also used the lashing method to build the external framework of the stadium (Fig. 6). Thus, the traditional connection joints of bamboo structure can also show more possibilities in modern raw bamboo buildings.

Traditional bamboo buildings are usually fixed by the combination of mortise-tenon joints and lashing joints. Rope binding makes it difficult for mortise-tenon joints to crack and loosen, so as to improve the reliability of the joints, and also make the stress distribute at the joints relatively more reasonable. However, the effect of this combination is still unsatisfactory. The hollow material characteristics of raw bamboo, the low strength and poor durability of tie rope are inevitable. In the using process, the components at the joints are prone to slip and fall off, which results in the overall strength of the structural system reduced or even the structure destroyed.

\section{Modern Connection Joints in Bamboo Structures}

Modern use of the raw bamboo building has higher requirements. In order to fully exploit the material properties of raw bamboo, it is necessary to adopt a more reasonable form of structural stress and a more precise form of joint construction. Compared with the two traditional joints mentioned in the above, the use of metal connectors as a medium to connect raw bamboos can effectively solve the problems of poor durability, as well as the components at the joints easy to slip off and so on. The essential difference between modern joints and traditional joints is that force is firstly transmitted to metal connectors, and then to other raw bamboo components, while traditional joints transmit force directly through overlapping bamboo. Prefabricated specific metal connectors can also create more complex forms of joint, so as to create more abundant structural and spatial types to meet the practical and artistic requirements of modern architecture.

\subsection{Bolted Joints}

Bolts are the most widely used metal connector (Fig. 7), which have the characteristics of good economic performance, high construction efficiency, simple and reliable transmission of force. The simplest bolt connection only needs to drill holes suitable for bolt diameter on the bamboo rod, and then matching bolts and nuts can realize the connection between the bamboo components. Other forms of bolt connection are optimized and improved on this basis.

Fig. 8 illustrates the simplest form of bolt connection, using only one bolt rod and a pair of nuts to complete the connection. Fig. 9 illustrates another common form of bolt connection. Two bolts are used to penetrate two bamboo members respectively, one of which has a hook at the end and two bolts are connected by the hook. The advantage of this kind of connection form is that it solves the difficult connection problem by using simple construction method, but there are also some problems such as insufficient strength of joints and easy shedding of the bending hook. Chinese architect Wang Shu designed a bolted joint (Fig. 10). He added U-shaped iron parts to the inner wall of raw bamboo. There are two metal sheets on the iron part, which is fixed by bolts to the inner wall of raw bamboo. The metal sheets contained in the joint alleviate the extrusion effect of nuts on the bamboo rod to some extent, but compared with the joint in Fig. 9, the raw bamboo is easy to rotate only under the fixing of the bolt, which may lead to instability.

Some scholars have carried out experimental researches on the performance of bolted joints of raw bamboo structure around factors such as the end distance and diameter of the bolts. Sonar et al. [37] studied the mechanical properties of single bolted and double bolted joints of bamboo members under axial tension. The results showed that different end distance and bolt diameter would affect the ultimate bearing capacity of the joints. The ultimate failure stress of double-bolt joints was higher than that of single-bolt joints. Based on the experimental data, the design values of theoretical calculation parameters were suggested. Moreira et al. [38] analyzed the nonlinear pressure distributions at the contact area of bolt in a bamboo circular hole through finite element analysis and experiment, considering the anisotropy and heterogeneity of the functionally graded material. It was found that the local stress was relatively high, and local reinforcement such as applying natural fiber straps close to the hole was suggested. Compared with results of simplified 
constitutive models (isotropic and homogeneous), the assumption of the bamboo as an orthotropic material was more reliable.

Masdar et al. [39] studied the critical value of the end distance of bolt on bamboo connection through experiments and considered the two main failure modes of shear failure and compressive failure. The results showed that when the two failure modes occurred simultaneously, the critical distance of bolt to the end of bamboo culms is 4-5 times the diameter of bamboo. Oka et al. [40] conducted an experimental and theoretical investigation of shear single connection and shear double connection without void filled material, and considered the influence of bamboo thickness, bolt diameter and specific gravity on lateral strength.

$\mathrm{Hu}$ et al. [41] investigated the bearing capacity and failure mode of bolted joint of prefabricated raw bamboo structure by static loading experiment. The study showed that the joints could effectively avoid the brittle failure and fully utilize the plastic performance of bolt under certain connection configurations, and also showed that the use of doubled bolted joint could significantly improve the bearing capacity. Trujillo et al. [42] obtained predictive equations for three connection design properties (dowel embedment strength, slip modulus and screw withdrawal capacity) through experiments, which were based on fastener diameter, density and bamboo wall thickness. Compared with similar equations contained in Eurocode 5, the calculation results showed that predictive equations were appropriate for bamboo.

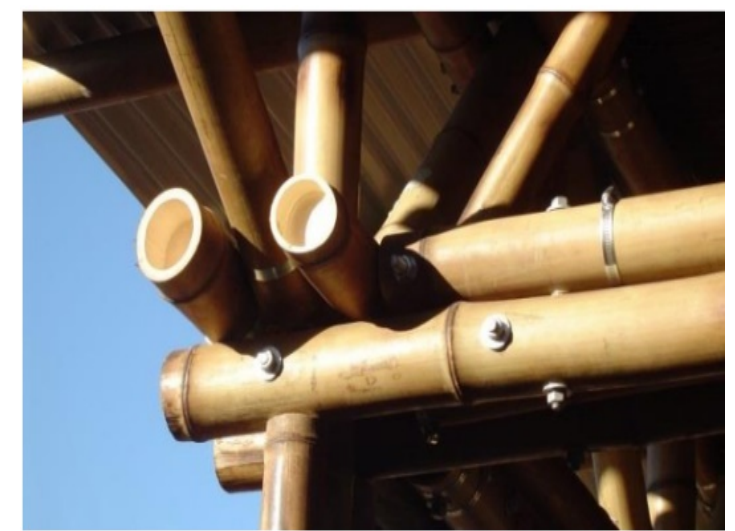

Figure 7: Bolted joint [33]

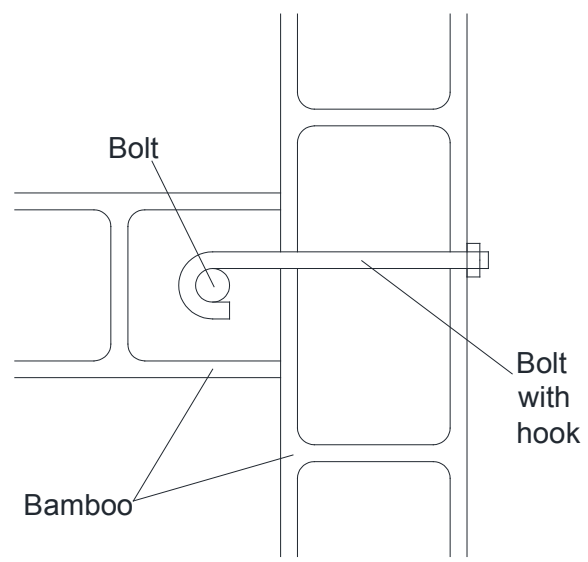

Figure 9: Bolted joint with hook [36]

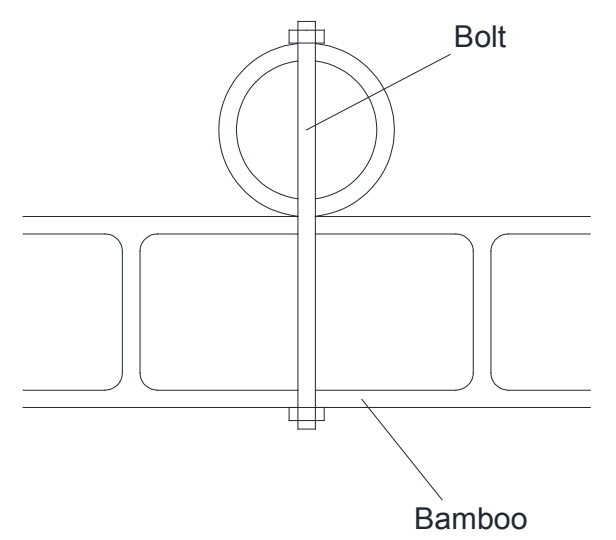

Figure 8: Simple forms of bolted joint [36]

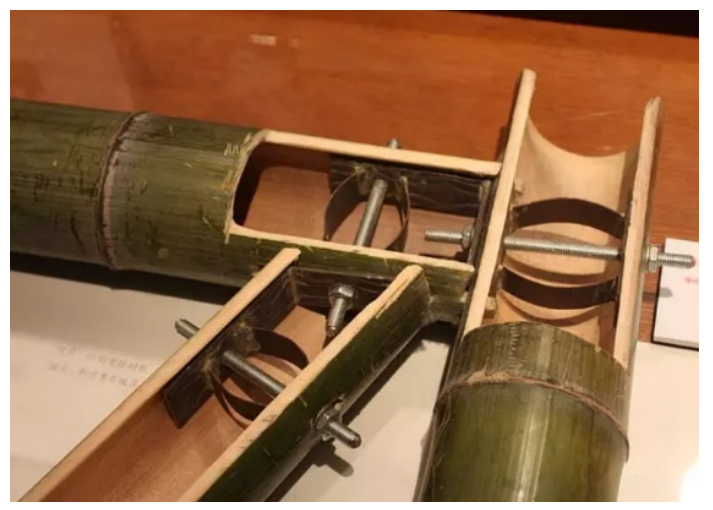

Figure 10: Wang Shu jointing method [34]

Bolted connections require high shear and splitting resistance of raw bamboo. Because of the hollow and thin-walled material characteristics, it is possible for raw bamboo to crack in the process of hole opening 
and in service, and the joints usually fail due to cracking or local deformation of bamboo culms [43]. In the construction process, it is difficult to ensure that the bolt holes of multiple bamboo poles are in a straight line. Although the diameter of the boreholes can be adjusted, this treatment can easily cause larger errors and reduce the strength of the joints. In addition, in the use process, because the bolts and nuts cannot fully fit with the round bamboo pole, the joint may gradually create gaps and loosen, and the bolts and nuts may rust and aging in the natural state as well, which may lead to unreliable connections, thus affecting the stability of the structure. Besides, the use of bolts requires a good understanding of structural design principles and the principle of triangulation, as once the structure is built it is difficult to remove and replace bamboo poles [33].

\subsection{Steel Member and Steel Plate Joints}

The joints connected by steel members (Fig. 11) are formed by bolts, rebar hooks, steel pipes, hoseclamps, etc. which have the characteristics of strong connection, convenient assembly and disassembly, and can be applied to the connection in various forms.

Fig. 12 shows a T-shaped steel pipe. The bamboo is directly inserted into the steel pipe and then fixed by bolts to achieve the connection between components. Steel pipe makes the components integral so that it can enhance the performance of the joint. However, because the size of prefabricated steel pipe is fixed and the diameter of raw bamboo is difficult to unify, it is necessary to cut the bamboo to match the inner diameter of the pipes, which not only weakens the performance of raw bamboo, but also increases the difficulty of construction. Fig. 13 shows a common prefabricated steel member that can connect multiple bamboo culms. Each steel pipe on the steel member is inserted into the interior of the bamboo pole, then the bamboo and the inner steel pipe is fixed together through two sets of bolts and nuts. Nevertheless, due to the difference between the shape of steel pipe and the inner shape of raw bamboo, the steel pipe and the bamboo cannot be closely attached. The relative position of the two has been changing, resulting in frequent changes in bolts of the main load. When the load is large, the bamboo wall is easy to be destroyed.

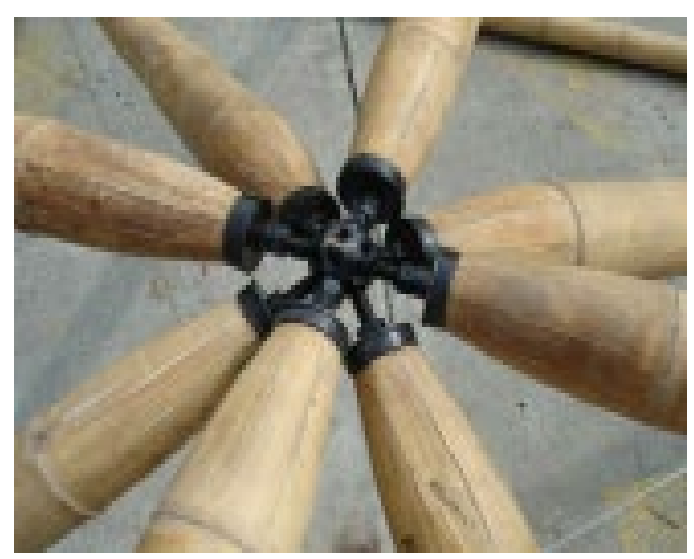

Figure 11: Steel member joint [34]

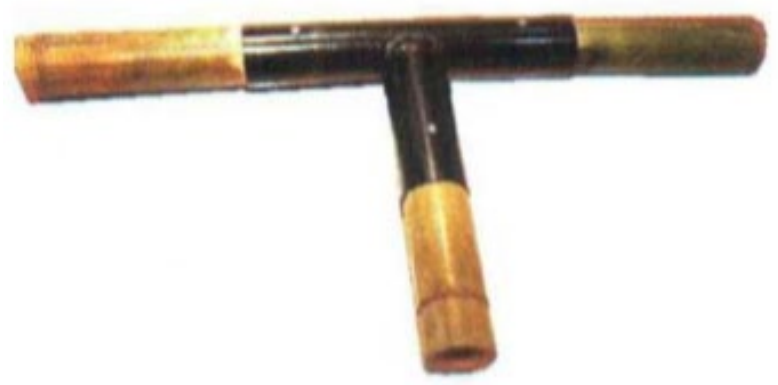

Figure 12: T-shaped steel pipe [34] 


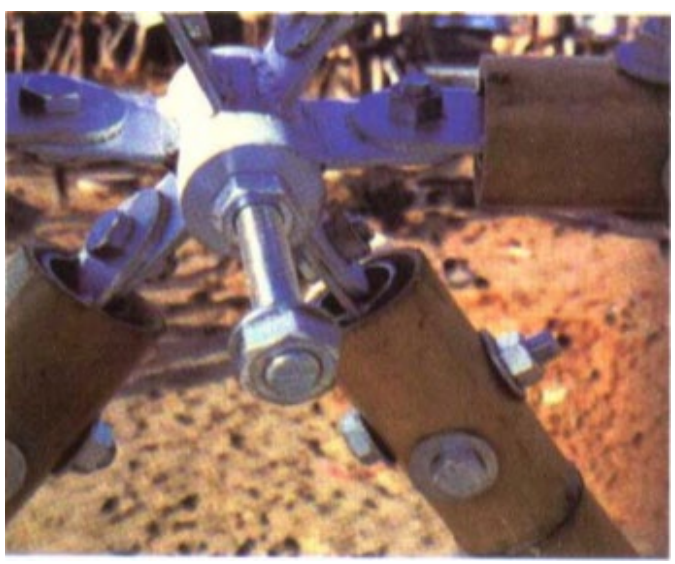

Figure 13: Common form of steel member joint [34]

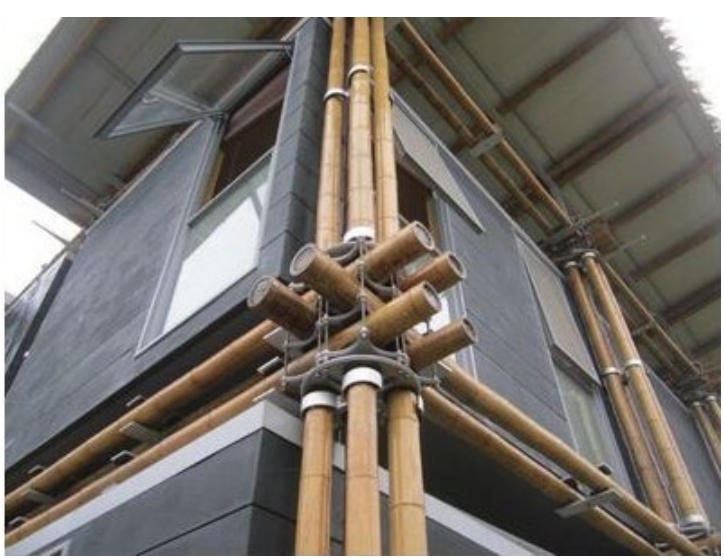

Figure 14: Multi-layer metal cage [44]

Studio Cardenas team [44] designed a multi-layer metal cage for connecting beams and columns when building the bamboo residence in Baoxi Township, Longquan, Zhejiang Province (Fig. 14). The metal cage is composed of multi-layer metal plates and bolts. The distance between metal plates can be adjusted by nuts to adapt to different sizes of raw bamboo. This joint has less damage to the material itself and avoids drilling holes on the bamboo as much as possible. In addition, there is an elastic cushion on the metal plate, which can not only alleviate the extrusion of steel members on the bamboo, but also increase friction to reduce the slip and rotation of the bamboo.

Morán et al. [45-47] proposed three kinds of bamboo joints which can transmit moment. The main body of the three joints consists of five pairs of light-weight steel clamps tightened around the culms (Fig. 15), which are connected with steel angles and platens in different configurations. Through static monotonic and cyclic tests, it is found that the confinement of steel clamps on the bamboo members effectively avoids premature cracking at the joints. Compared with the traditional fish mouth joints [48] and mortar-injected bolted joints, the average stiffness and strength of these three joints are increased by at least $29 \%$ and $250 \%$. The hysteresis loops with pinched regions of the three joints are similar to those of wood joints, as the sliding of steel clamps causes the stiffness degradation but without strength degradation.

Paraskeva et al. [49] considered the influence of end distance and hose clamps restraint on the joint performance. The test results show that the transverse confinement provided by hose clamps can effectively prevent the brittle splitting behavior at the joint. Combined with adequate end distance, the strength and ductility of the joint can be significantly improved.

The joints connected by the steel plate (Fig. 16) are drilled steel plates in multiple directions on a central steel member, which are formed by connecting with bamboo through bolts, metal washers, clamps, hubs, etc. Sonar et al. [37] has proved through theoretical calculation and experiment that the joint efficiency increases due to provision of inner splints. 


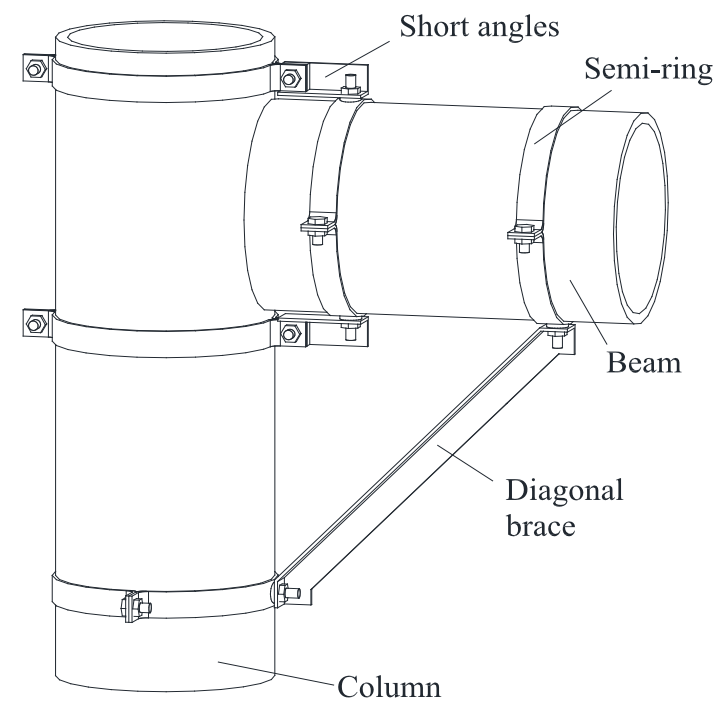

Figure 15: Moran jointing method [45]

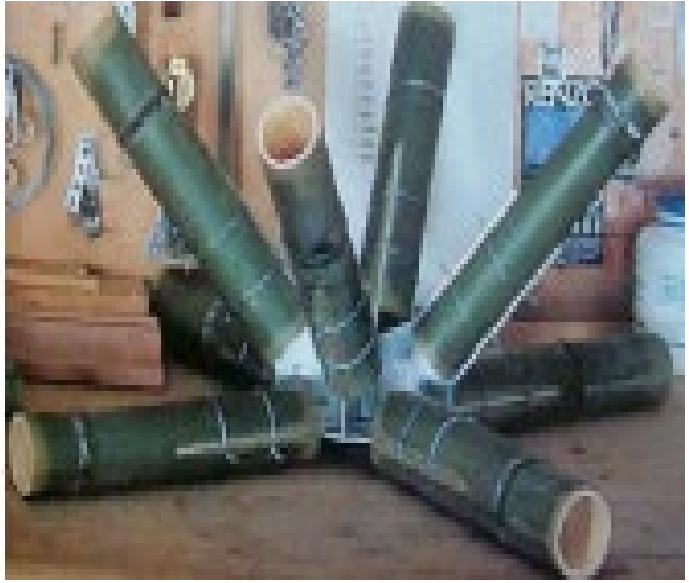

Figure 16: Steel plate joint [28]

Fig. 17 shows a simple form of steel plate joints. In the middle of the component is a regular hexagonal steel plate. Six bamboos are fixed together with the steel plate through bolts. This kind of joint can easily connect several bamboo components intersecting in the plane, but the strength of the joint cannot be guaranteed because the bamboo is simply connected with the steel plate through bolts.

There are many styles of steel members and steel plates. According to different parts of structures and usage requirements, people combine bamboo with prefabricated metal connectors to create a variety of joint forms (Figs. 18-22). Prefabricated metal connectors are highly accurate, durable, insect-resistant and moisture-proof, some of them can also be recycled. However, as the cross-section shape, diameter and height of naturally grown bamboo are different, it is difficult to unify the specifications of raw bamboo. It will inevitably cause a lot of waste to connect bamboo with precise steel joints. In addition, the design and fabrication of joints is usually only for a specific project. The fabrication process is complex and expensive, and cannot be industrialized in mass production, which has great limitations in the wide application.

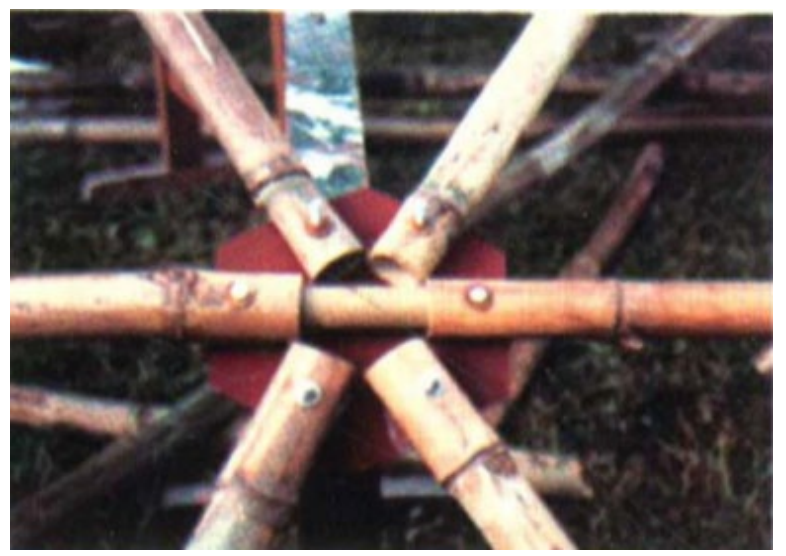

Figure 17: Simple steel plate joint [34]

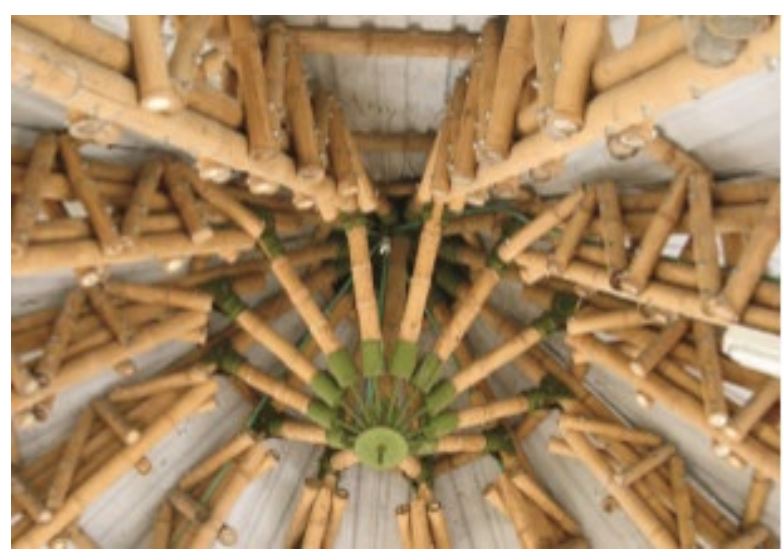

Figure 18: Complex steel member joint [50] 


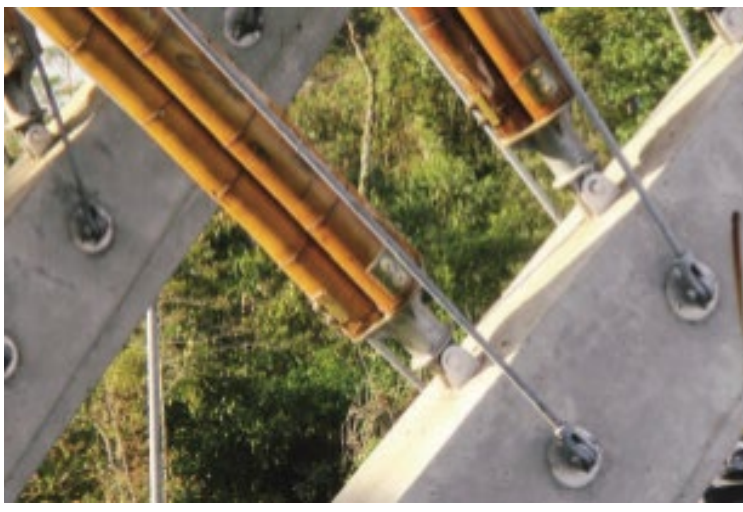

Figure 19: Connection between raw bamboo and concrete [50]

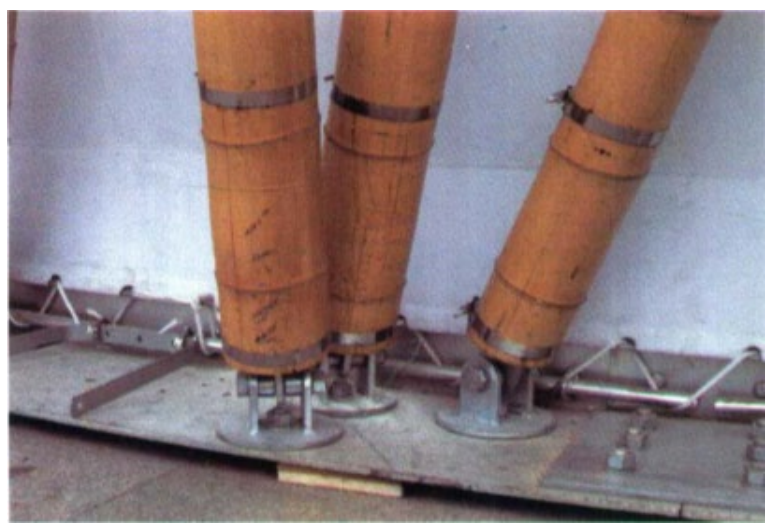

Figure 21: Connection between raw bamboo and floor [34]

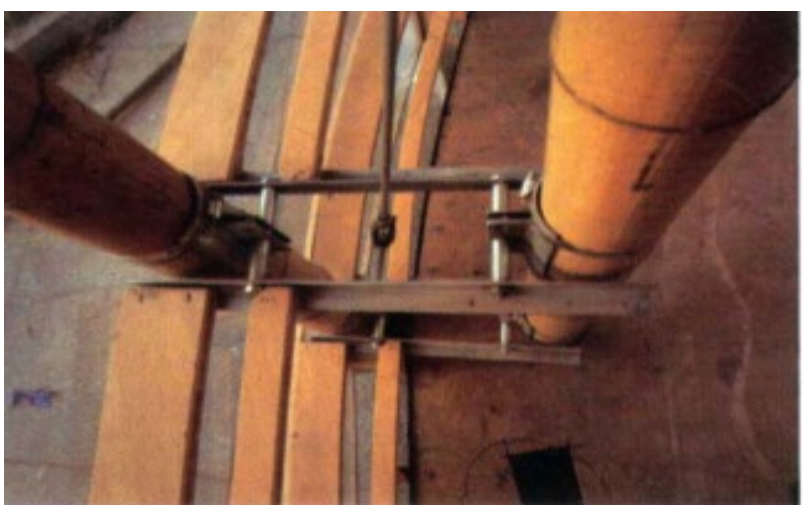

Figure 20: Connection between main structure and enclosure structure [34]

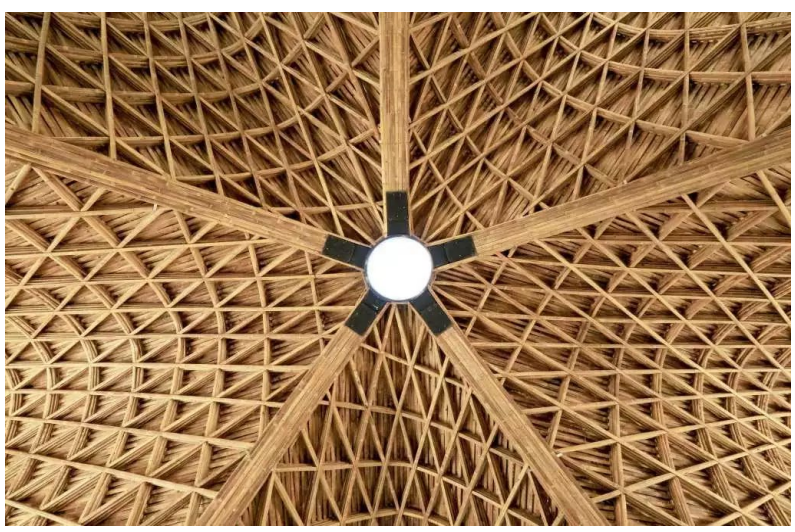

Figure 22: Steel member joint in Bamboo Luum Temple [51]

\subsection{Filler Reinforced Joints}

Most of the existing joints connected by metal connectors need to deal with raw bamboo, such as opening bolt holes and converging the ends (Fig. 23). These treatments weaken the performance of bamboo components and make the raw bamboo at the joints easy to crack. In order to ensure the stiffness and stability of the joints, scholars put forward the joint forms which are strengthened by adding fillers into the bamboo cavity, and then connected by bolts and prefabricated metal connectors.
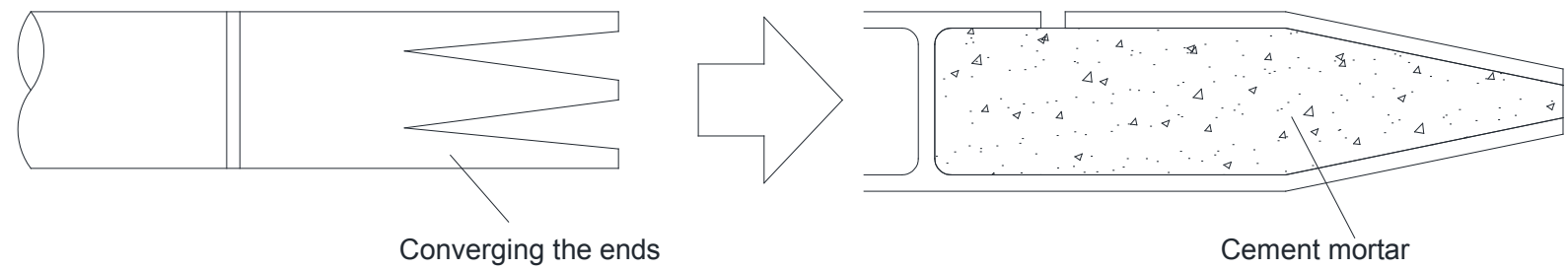

Figure 23: Converging the ends of bamboo [36]

Architect Simon Velez [52] used cement mortar to enhance the performance of joints in a large number of raw bamboo building works (Fig. 24). The results of practical application demonstrate the good mechanical properties and processability of the mortar-injected joints. However, in order to avoid excessive drilling damage to bamboo, the actual diameter of the borehole is only slightly larger than the diameter of 
bolts, which makes the filling of cement mortar more difficult. In addition, due to the opacity of bamboo, the results cannot be observed in the grouting process, and the compactness of filling cannot be guaranteed.

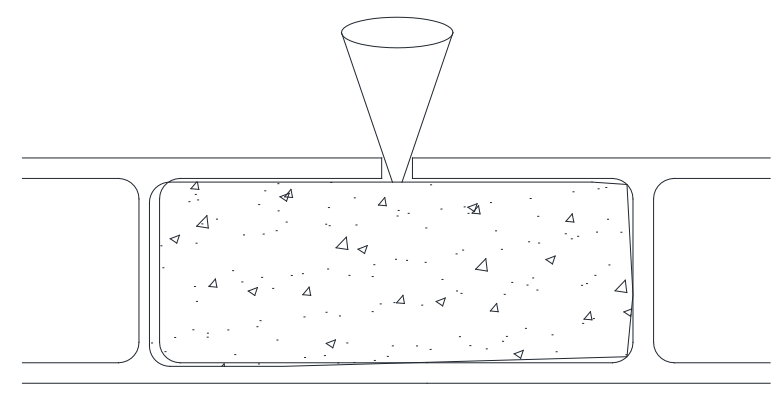

Figure 24: Pouring cement mortar through a funnel [36]

Scholars have carried out experimental studies on the reinforced bamboo joints with fillers. Hu et al. [41] investigated the mechanical properties of strengthened bolted joint with high-strength mortar. The results revealed that the bolted joints reinforced with cement motar could improve the bearing capacity significantly. Based on laboratory test results, theoretical formula was derived. Correal et al. [53] studied the embedding strength of mortar-injected joints through experiments. It was found that the compressive strength of cement mortar played a decisive role in the bearing capacity of joints. Based on the European yield theory [54], a theoretical formula for calculating mortar-injected bolted joints was proposed. Morisco [55] proposed an extension connection form of bamboo. First, cement mortar was injected into the cavity of two bamboos, and then bolts and steel plates were used to improve the strength and ductility of the joints (Fig. 25). However, the weight of joints as well as the structures has increased by at least 2.5 times [56], and in the case of long-term use, due to the different shrinkage-swelling rates of cement mortar and bamboo, cracks gradually occurs between the materials so that the materials are separated from each other and cannot continue to work together.
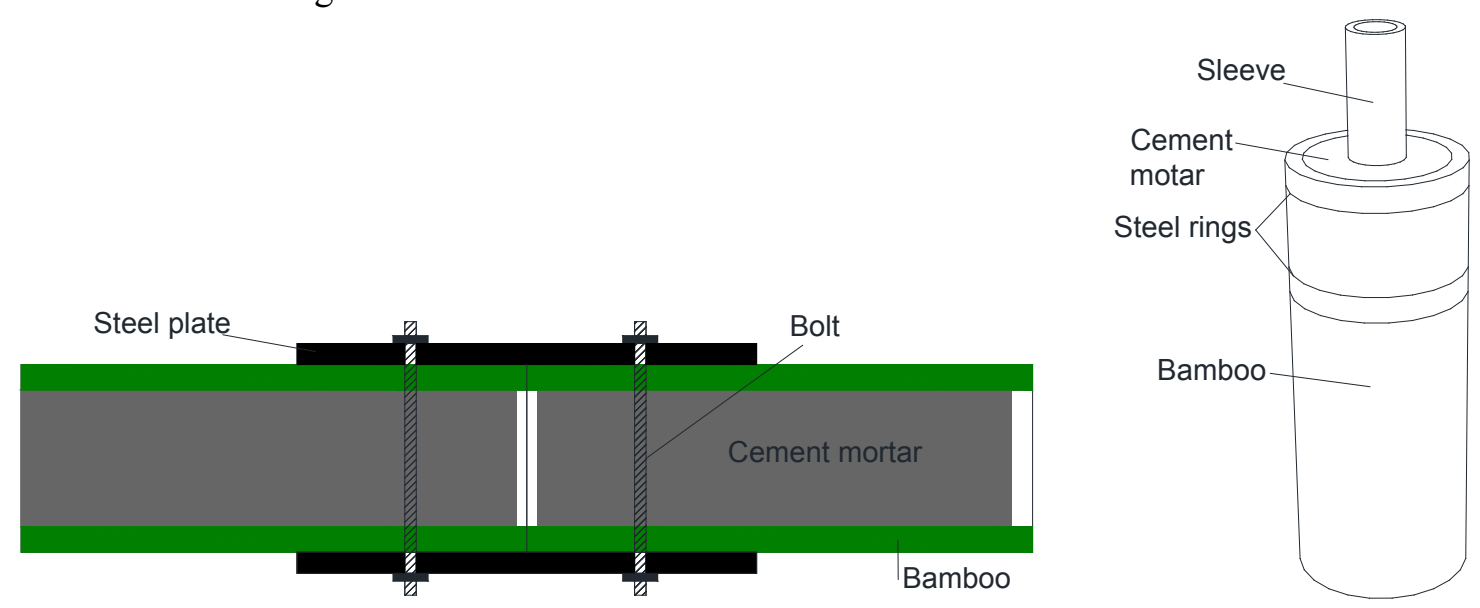

Figure 25: Morisco jointing method [56]

Figure 26: Fu jointing method [57]

Fu et al. [57] designed a kind of joint, in which the prefabricated steel sleeve was first inserted into the cavity of raw bamboo, then the cement mortar was injected between the sleeve and the bamboo wall, and finally the joint was restrained by steel rings (Fig. 26). The results of tension and compression tests showed that the joint had good ductility and high strength, and could effectively transfer the axial load. Cabanas [58] designed an orthogonal mortar infilled steel eyebolt connection with a fish-mouth cut, and tested the connection under bending, shear and cyclic loads. The results indicated that cement mortar infilling increased the shear capacity of the connection, and successfully prevented local splitting failure of the 
bamboo despite more than doubling the weight of the connection. Paraskeva et al. [49] found through monotonic loading tests that the mortar infill resulted to connections of higher strength, compared to joints restrained by hose clamps, but often at the cost of reduced ductility.

Inoue et al. [59] proposed a joint which used bamboo strip to fill and bamboo connector [60] to connect (Fig. 27(a)). The test results indicated that the joint showed high rigidity until near the peak of load, and the joint was ultimately damaged by the pull-out of the bamboo connector due to the failure of the adhesive. This type of joint has fine appearance and good environmental performance because of using no metal. Compared with mortar-injected joints, the joint uses two materials with similar shrinkage-swelling ratio, which effectively reduces the possibility of cracks between materials. However, this kind of joint also has some shortcomings, such as long filling time and inconvenient filling, so improvement of better filling materials and filling methods is needed.

Inoue et al. [59] also proposed a joint consisting of steel rings and cup with plaster (Fig. 27(b)). The test results showed that the friction effect between the bamboo and the steel ring cannot be fully exerted because of the presence of the gap, and the joint was eventually destroyed by the dislocation of the steel ring and the surface of the bamboo. Zhang [61] used plaster and additives as fillers to fill the hollow parts of raw bamboo. Through research, it is found that the joints filled with plaster was similar to solid wood components, and has high hardness and good machinability. It is suggested to refer to the mature joint technology of steel and wood structure to solve the problem of joints in raw bamboo buildings. Bi [62] also carried out an experimental study on the performance of joints filled with plaster and additives, and obtained similar conclusions.

These researches show that filling the hollow parts of the bamboo with appropriate filler materials is an effective method to improve the performance of the building joints of the bamboo. The strength, ductility, machinability and reliability of filled joints have been improved to some extent, but there are still many shortcomings in terms of filler selection, construction convenience and long-term use effect. In the future, further research can be done on the selection of better material and improvement of filling methods.

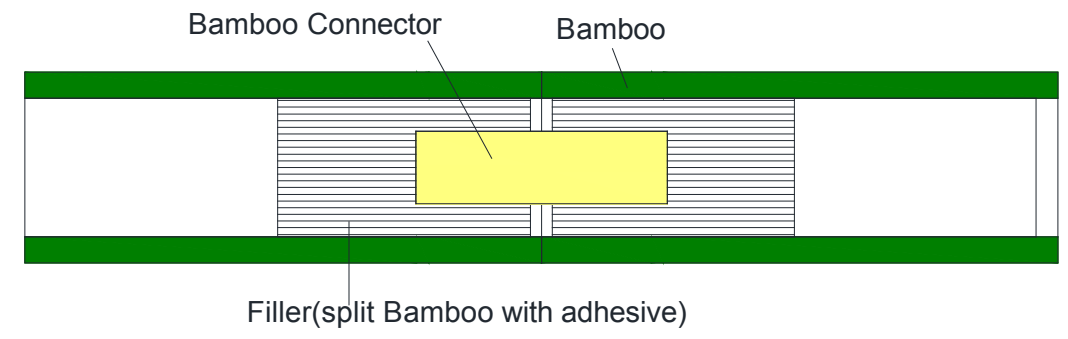

(a) Joint filled with bamboo strips

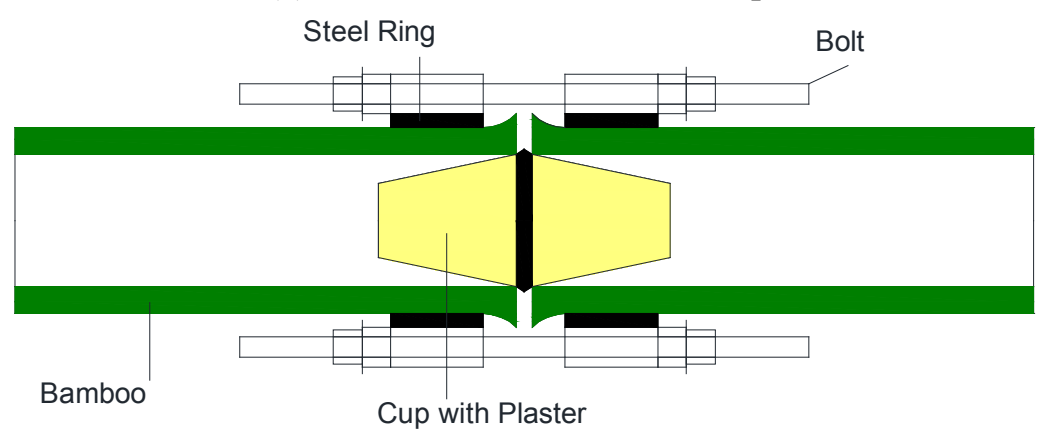

(b) Joint filled with plaster

Figure 27: Inoue jointing method [59]

\subsection{Other Types of Joints in Bamboo Structures}

Scholars have studied other types of connection modes in bamboo structure. Bacthiar [63] proposed a 
jointing method (Fig. 28) with special steel tubes attached to both ends of raw bamboo. The joint is composed of steel tubes, wood blocks and steel rods. Its axial bearing capacity depends on the shear strength of the adhesive layer between the wood blocks and the bamboo enclosed by the tube. The bamboo components are connected with each other by the steel bar at the end, so that the complex assembly can be easily realized. Ohta et al. [64] proposed a jointing method (Fig. 29) that flattened the end of raw bamboo. The production of joint firstly removes some parts of the end of the bamboo and the inner skin of bamboo, then uses adhesive to bond the bamboo with the wood block, and finally presses into a regular whole under heat treatment.

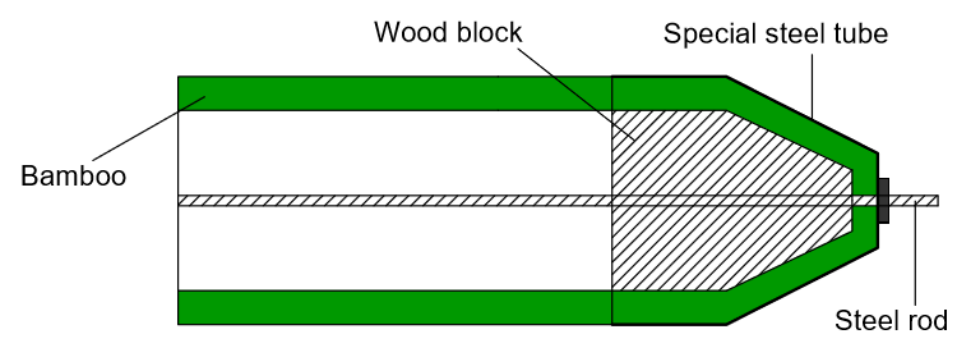

Figure 28: Bacthiar jointing method [56]

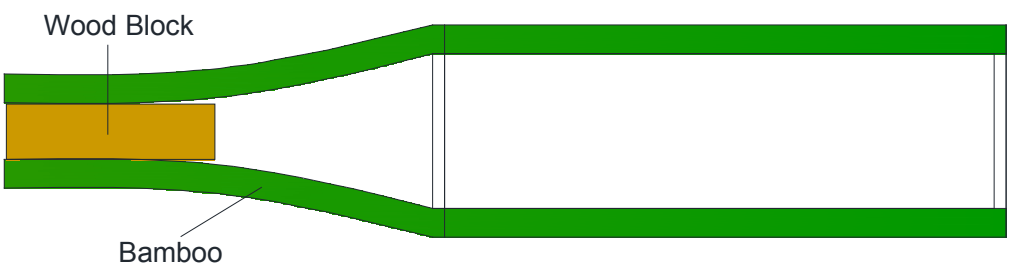

Figure 29: Ohta jointing method

Huang [65] conducted a shear test on the raw bamboo joints reinforced with CFRP (carbon fiber reinforced plastics/polymer). The results showed that the shear strength of the joints strengthened with single-layer sheet can be significantly increased by $18.4 \%$. The strength of the joints strengthened with twolayer sheets is only slightly improved compared with that strengthened with single-layer cloth. Awaludin et al. [56] compared the mechanical properties of joints strengthened with natural fiber (Indonesian name, "ijuk") and fiber reinforced plastic (Fig. 30). It was found that the slip modulus and bearing capacity of joints strengthened with FRP sheet had been greatly improved. The wrapping effect caused by FRP sheet effectively postpones the splitting of bamboo, while the effect caused by natural fiber is not significant.
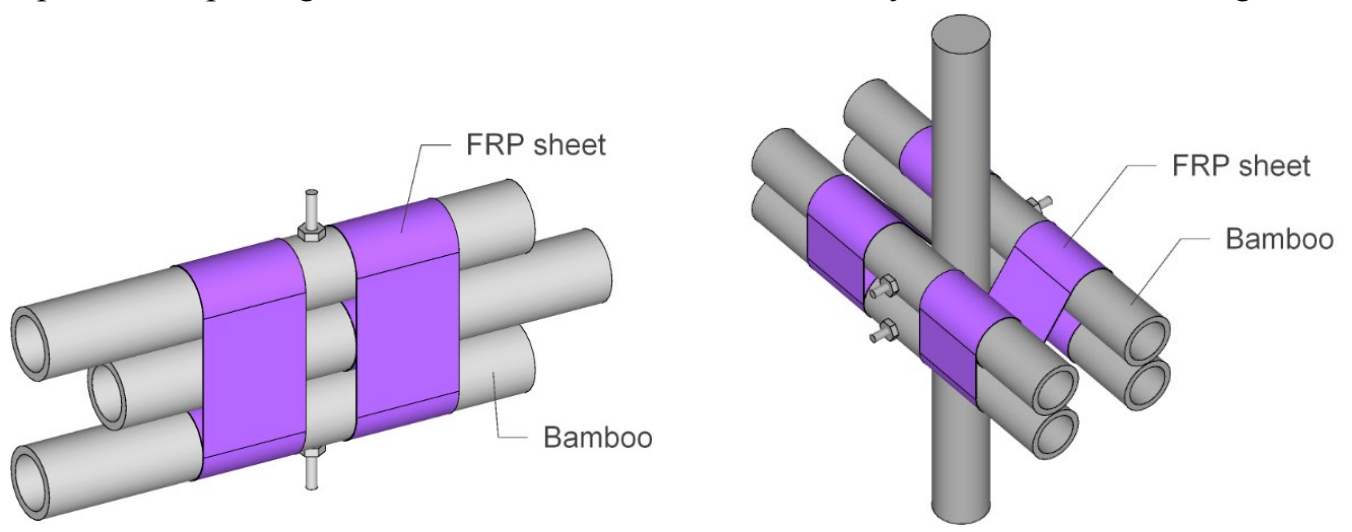

Figure 30: Awaludin jointing method [56]

Zhang et al. [66] proposed a jointing method of bamboo-wood cup joints with wooden mortise-tenon joints. Through Etabs calculation of a two-story bamboo frame structure, and finite element analysis of the intermediate joint with Abaqus, the safety and feasibility of the joint were proved. The advantage of this 
joint is that it converts the connection problem between raw bamboo into the connection problem between bamboo and wood and the wooden members. Therefore, the mature joint technology of wood structure can be used to realize the connection between bamboo components.

Masdar et al. [67] proposed a lightweight joint including bolts, special wooden clamps and wooden gusset plates for the truss connection of raw bamboo (Fig. 31). The shape and angle of wooden clamps have been adjusted according to the shape and size of raw bamboo. The test results showed that the load-bearing capacity of joints with wooden clamps is increased by about $40 \%$ compared with the joints without wooden clamps. Masdar et al. [68] analyzed the influence of bolt tightening force on the performance of this lightweight joint through experiments, and the appropriate values of bolt tightening force were obtained. Masdar et al. [69] also studied the influence of stem's angle at the joint, and found that there was a decrease in the strength and stiffness of the joints along with the increase in stem's angle of the bamboo.

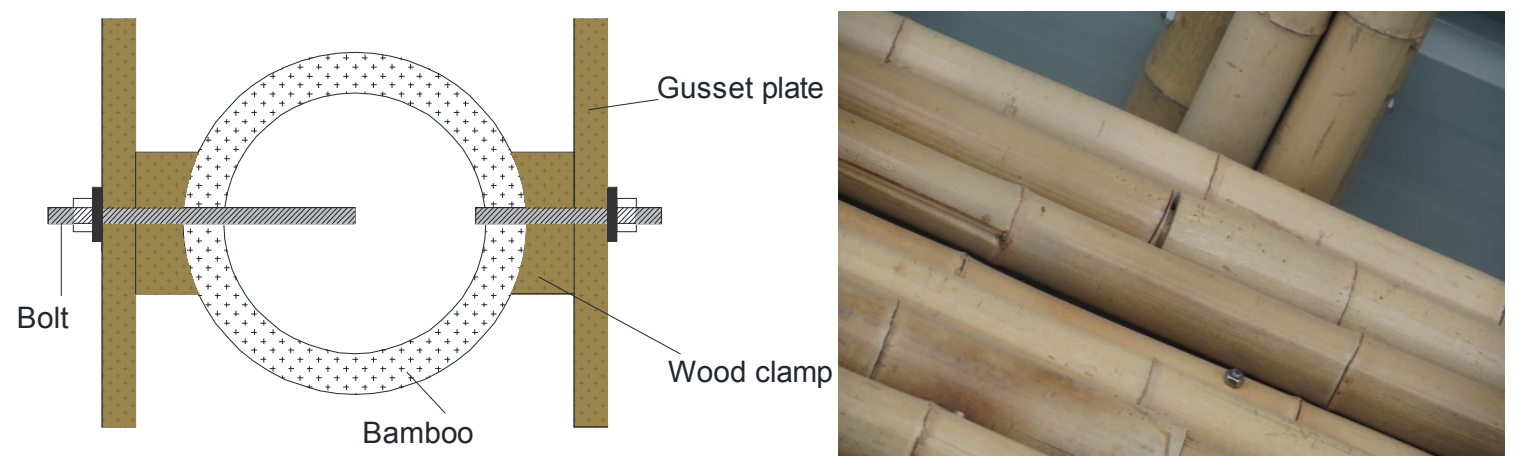

Figure 31: Masdar jointing method [67]

Figure 32: Sleeve joint of bamboo poles [70]

At the Beijing International Horticultural Exhibition in 2019, Italian architect Ma Ruxiao and Chongqing University architect Wang Xuesong jointly designed the International Bamboo and Rattan Exhibition Garden. The research team has developed the extension technology of connecting large and small bamboo poles by air nails (Fig. 32). Because of the same material characteristics and similar performance between the small bamboo pole and the large bamboo pole, this operation can not only make the bamboo poles deform synchronously but also be adjusted to the similar radian well. The process is simple and it is a good raw bamboo connection technology.

Lefevre et al. [71] proposed a bamboo culm-to-culm joint, which consists of custom-machined wooden block and metal hose-clamps (Fig. 33). Bamboos can be connected to wooden blocks through machined pegs which are inserted inside the culms and are secured with hose clamps. The test results showed that the best design configuration had a bending strength of $88.4 \mathrm{MPa}$ and a shear strength of $18.5 \mathrm{Mpa}$, which used two hose clamps located at the two ends of the peg. This type of joint is cheap and easy to make, but each individual joint need to be fabricated to fit the bamboo culms being used.
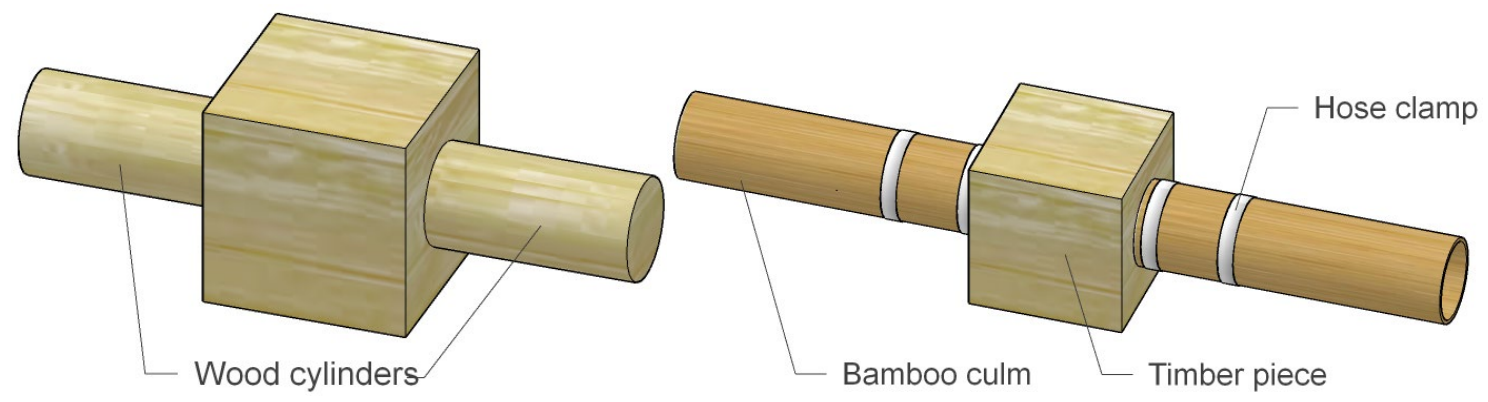

Figure 33: Lefevre jointing method [71]

Matson et al. [72] created a customised joint system fabricated by three-dimensional printing (Fig. 34). A parametric software is used to quickly adapts to the irregularity of the bamboo. The joints suitable for 
connecting bamboo of different dimension are fabricated separately based on the program, thus the secure connection of each unique joint at each intersection is guaranteed and the construction waste can be reduced. Di Paola et al. [73] proposed the use of parametric modelling techniques as well (Figs. 35-36). The joint allows to determine and control parametrically the adaptability to any spatial grid configuration of culms with heterogeneous dimensions.
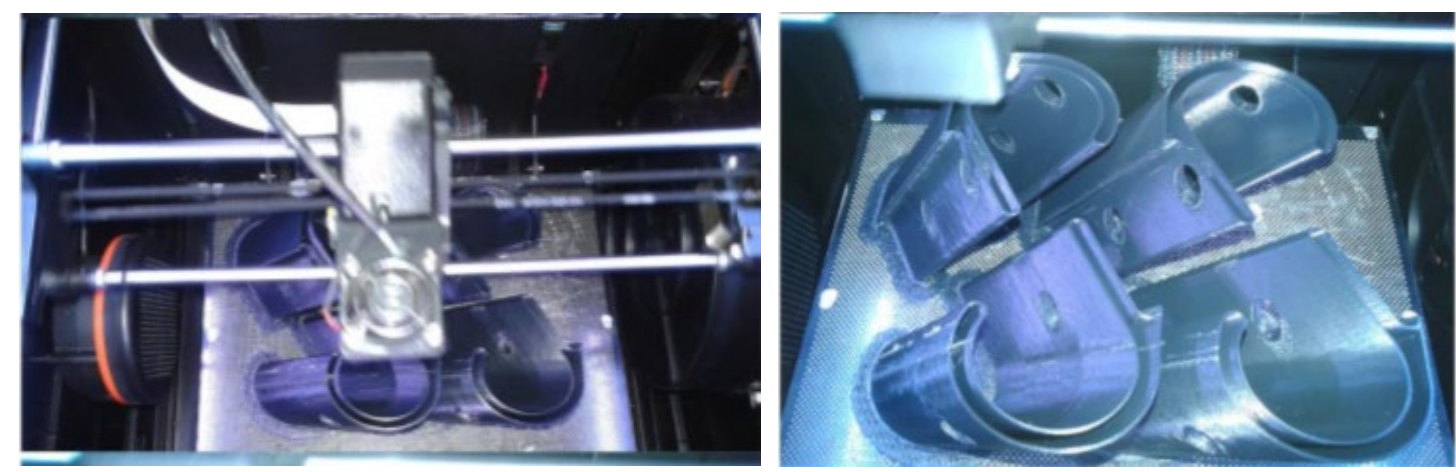

Figure 34: 3D printing 1:1 scale joints [72]

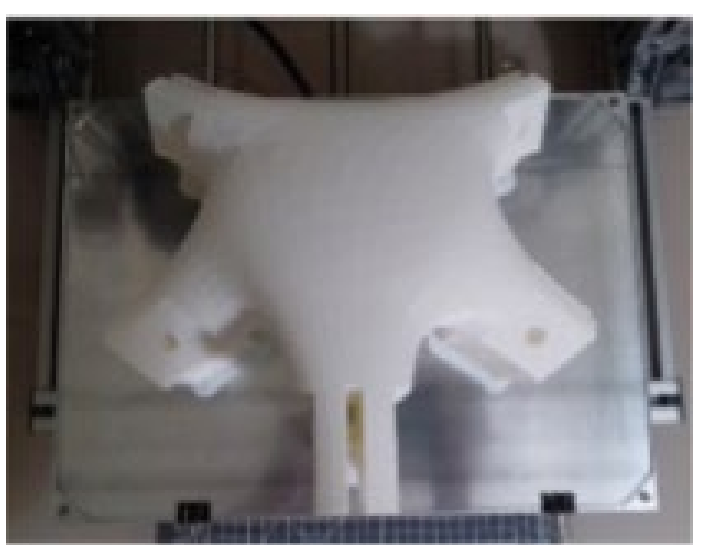

Figure 35: 3D printing process [73]

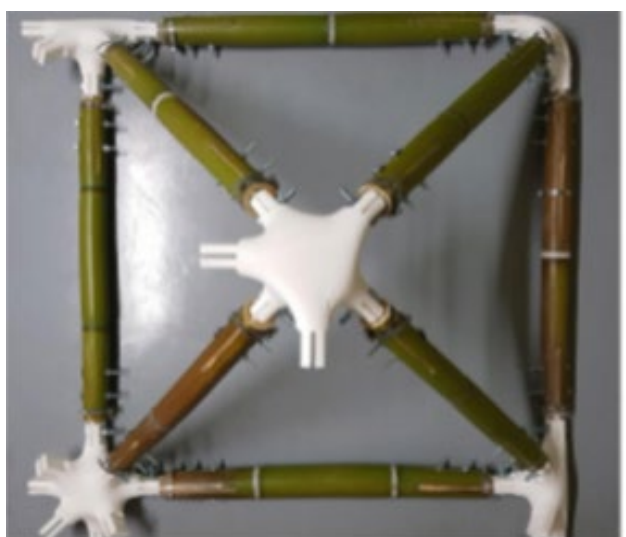

Figure 36: Prototype of a typical module of a full-scale spatial structure [73]

It can be seen that the other types of joints of the raw bamboo structure are mostly formed on the basis of lashing joints, bolted joints, steel member and steel plate joints and filler reinforced joints. Scholars combined the advantages of various joints and made corresponding improvements to the shortcomings, such as the replacement of materials, etc. and proposed a series of novel and reliable forms of joints, which fully exerted the mechanical properties of the bamboo itself.

\section{Conclusion}

The damage of building structures mostly originates from the failure of joints, which are the key to ensure the structural load transfer and the resistance force of the structure. The mechanical properties at the joints are complex and the influencing factors are numerous. The design of durable, safe and reliable joints and the establishment of design theory and calculation system for the joints of bamboo structure have important practical significance for the promotion and application of bamboo structures.

Although scholars have researched various kinds of joints according to the material characteristics of raw bamboo and carried out some experimental studies on them, the existing jointing methods are not completely satisfactory. There are problems of bearing capacity, stiffness, durability and construction efficiency in different degrees, so it is urgent to develop safe, reliable and easy-to-operate raw bamboo joints. From the perspective of economy, excellent joint requires a balance between performance and 
economy as well. It is difficult to unify the dimensions of raw bamboo. The irregularity of raw bamboo makes the production of steel members and steel plates expensive and difficult to industrialize mass production. Therefore, improving the automation degree of production and reducing the cost are also the key to break through the bottleneck of the development of bamboo buildings. At present, the number of tests on the bamboo joints is far from enough compared with timber structures, so it is necessary to carry out a large number of experiments and theoretical studies to comprehensively and systematically establish the design system of raw bamboo connections.

In addition to the performance of joints, the mechanical properties of the basic material are important as well, namely the bearing strength, shear strength and tensile strength perpendicular of grain, which significantly influences the overall connection behavior. Although the resources of bamboo are sufficient, and it is a green construction material which supports sustainable development strategies, due to its low capacity and easy-to-crack property, bamboo structures are less popular in today's civil construction. During service, most of the failure of the joints proposed by researchers generally occurs in bamboo culms instead of joint area, thus, more researches should also be carried out to find some ways to improve the load capacity and anti-splitting performance of bamboo.

Acknowledgment: The research work presented in this paper is supported by the Natural Science Foundation of Jiang-su Province (No. BK20181402), the National Natural Science Foundation of China (51878354), National Key R\&D Program of China, the Open Fund Project from Key Laboratory of Concrete and Pre-stressed Concrete Structure of Ministry of Education (Southeast university), the China Postdoctoral Science Foundation (2015M580382), Jiangsu Postdoctoral Science Foundation Project (1501037A), Qing Lan Project, and a Project Funded by the Priority Academic Program Development of Jiangsu Higher Education Institutions. Any research results expressed in this paper are those of the writer(s) and do not necessarily reflect the views of the foundations.

\section{References}

1. He, M. J., Zhang, J., Li, Z., Li, M. L. (2016). Production and mechanical performance of scrimber composite manufactured from poplar wood for structural applications. Journal of Wood Science, 62(5), 429-440.

2. Zhang, L. F., Liu, W. Q., Wang, L., Ling, Z. B. (2019). Mechanical behavior and damage monitoring of pultruded wood-cored GFRP sandwich components. Composite Structures, 215, 502-520.

3. Wang, Z., Wang, Y. L., Cao, Y., Gao, Z. Z. (2018). Measurements of the shear modulus of materials by the freeplate torsional mode shape method. Journal of Testing and Evaluation, 47(2), 1163-1181.

4. Chen, Z., Zhang, H., He, Z., Zhang, L., Yue, X. (2018). Bamboo as an emerging resource for worldwide pulping and papermaking. BioResources, 14(1), 3-5.

5. Kumar, A., Vlach, T., Laiblova, L., Hrouda, M., Kasal, B. et al. (2016). Engineered bamboo scrimber: influence of density on the mechanical and water absorption properties. Construction and Building Materials, 127, 815-827.

6. Zhang, H. Z., Li, H. T., Corbi, I., Corbi, O., Wu, G. et al. (2018). AFRP influence on parallel bamboo strand lumber beams. Sensors, 18(9), 2854.

7. Li, H. T., Qiu, Z. Y., Wu, G., Corbi, O., Wei, D. D. et al. (2019). Slenderness ratio effect on eccentric compression properties of parallel bamboo strand lumber columns. Journal of Structural Engineering, 145(8), 04019077.

8. Li, H. T., Su, J. W., Deeks, A. J., Zhang, Q. S., Wei, D. D. et al. (2015). Eccentric compression performance of parallel bamboo strand lumber columns. BioResources, 10(4), 7065-7080.

9. Li, H. T., Qiu, Z. Y., Wu, G., Wei, D. D., Lorenzo, R. et al. (2019). Compression behaviors of parallel bamboo strand lumber under static loading. Journal of Renewable Materials, 7(7), 583-600.

10. Li, H. T., Zhang, Q. S., Wu, G., Xiong, X. H., Li, Y. J. (2016). A review on development of laminated bamboo lumber. Journal of Forestry Engineering, 1(6), 10-16.

11. Li, H. T., Wu, G., Xiong, Z. H., Corbi, I., Corbi, O. et al. (2019). Length and orientation direction effect on static bending properties of laminated Moso bamboo. European Journal of Wood and Wood Products, 1-11. 
12. Li, H. T., Liu, R., Lorenzo R., Wu, G., Wang, L. B. (2019). Eccentric compression properties of laminated bamboo lumber columns with different slenderness ratios. Proceedings of the Institution of Civil EngineersStructures and Buildings, 172(5), 315-326.

13. Li, H. T., Wu, G., Zhang, Q. S., Deeks, A. J., Su, J. W. (2018). Ultimate bending capacity evaluation of laminated bamboo lumber beams. Construction and Building Materials, 160, 365-375.

14. Li, H. T., Wu, G., Zhang, Q. S., Su, J. W. (2016). Mechanical evaluation for laminated bamboo lumber along two eccentric compression directions. Journal of Wood Science, 62(6), 503-517.

15. Xiao, Y., Li, Z., Wu, Y., Shan, B. (2018). Research and engineering application progress of laminated bamboo structure. Building Structure, 2018(10).

16. Wei, Y., Wu, G., Zhang, Q. S., Jiang, S. X. (2012). Theoretical analysis and experimental test of full-scale bamboo scrimber flexural components. Journal of Civil, Architectural \& Environmental Engineering, 34, 140-145.

17. Wei, Y., Jiang, S. X., Lv, Q. F., Zhang, Q. S., Wang, L. B. et al. (2011). Flexural performance of glued laminated bamboo beams. Advanced Materials Research, 168, 1700-1703.

18. Sharma, B., Gatóo, A., Bock, M., Ramage, M. (2015). Engineered bamboo for structural applications. Construction and Building Materials, 81, 66-73.

19. Mahdavi, M., Clouston, P. L., Arwade, S. R. (2010). Development of laminated bamboo lumber: review of processing, performance, and economical considerations. Journal of Materials in Civil Engineering, 23(7), 1036-1042.

20. Li, H. T., Su, J. W., Zhang, Q. S., Deeks, A. J., Hui, D. (2015). Mechanical performance of laminated bamboo column under axial compression. Composites Part B: Engineering, 79, 374-382.

21. Li, H. T., Deeks, A. J., Zhang, Q. S., Wu, G. (2015). Flexural performance of laminated bamboo lumber beams. BioResources, 11(1), 929-943.

22. Huang, M. X., Zhang, X. C., Yu, W. J., Li, W. Z., Liu, X. M. (2016). Mechanical properties and structure characterization of bamboo softened by high temperature steam. Journal of Forestry Engineering, 1(4), 64-68.

23. Chen, G., Zhou, T., Li, C. L., Zhang, Q. S., Li, H. T. (2016). Experimental study on the OSB webbed bamboo beams. Journal of Nanjing Forestry University (Natural Science Edition), 40(5), 121-125.

24. Li, Y. J., Xu, B., Zhang, Q. S., Jiang, S. X. (2016). Present situation and the countermeasure analysis of bamboo timber processing industry in China. Journal of Forestry Engineering, 1(1), 2-7.

25. Hao, J. P., Qin, M. H., Tian, L. M., Liu, M., Zhao, Q. L. (2017). Experimental research on the mechanical properties of phyllostachys pubescen along the grain direction. Journal of Xian University of Architecture \& Technology (Natural Science Edition), 6, 777-783.

26. Zhou, J. W., Huang, D. S., Huang Z. R., Shen Y. R. (2018). Experimental behavior of fabricated beam-column connection of bamboo frame under monotonic loading. Journal of Forestry Engineering, 3(3), 122-127.

27. Fang, C. H., Jiang, Z. H., Sun, Z. J., Liu, H. R., Zhang, X. B. et al. (2018). An overview on bamboo culm flattening. Construction and Building Materials, 171, 65-74.

28. Zhang, N., Bai, W. F. (2008). Analyzing and improving the construction of bamboo house node. Science Technology and Engineering, 8(18), 5318-5322.

29. Liu, J. L., Guo, M. (2018). Seismic capacity analysis on timber structure buildings in Jingdezhen. Building Structure, 48(10), 18-24.

30. China Daily (2011). The Dai ethnic group's great wisdom: the bamboo house. http://www.chinadaily.com.cn/life/2011-01/05/content 11798460.htm.

31. Tian, L. M., Jin, B. B., Hao, J. P. (2018). Research and application of modern bamboo structures. Proceedings of the 27th National Conference on Structural Engineering, 1.

32. Seixas, M., Moreira, L. E., Bina, J., Ripper, J. L. M. (2018). Design and analysis of a self-supporting bamboo roof structure applying flexible connections. Proceedings of IASS Annual Symposia, 20, 1-9.

33. Vahanvati, M. (2015). The challenge of connecting bamboo. de 10th World Bamboo Congress.

34. Tan, G. Y., Yang, L. (2014). Tectonics of Bamboo. Nanjing: Southeast University Press.

35. Chiangmai Life Architect (CLA). Panyaden international school sports hall/bamboo architecture. https://www.bamboo-earth-architecture-construction.com/portfolio-item/panyaden-international-school-sportshall. 
36. Wu, S. L. (2018). Study of Bamboo architecture structural joint and its design expression (Ph.D. Thesis). Nanjing University, Nanjing, China.

37. Sonar, I. P., Siddhaye, V. R. (2009). Theoretical and experimental investigation on single and double bolted bamboo joint under axial tension. Journal of Structural Engineering, 36(3).

38. Moreira, L. E., Ghavami, K. (2012). Limits states analysis for bamboo pin connections. Key Engineering Materials, 517, 3-12.

39. Masdar, A., Suhendro, B., Siswosukarto, S., Sulistyo, D. (2014). Determinant of critical distance of bolt on bamboo connection. Jurnal Teknologi, 69(6).

40. Oka, G., Triwiyono, A., Awaludin, A., Siswosukarto, S. (2015). Experimental and theoretical investigation of bolted bamboo joints without void filled material. Applied Mechanics and Materials, 776, 59-65.

41. Hu, H., Yang, J., Wang, F. L., Zhang, Y. M. (2018). Mechanical properties of bolted joints in prefabricated round bamboo structures. Journal of Forestry Engineering, 3(5), 128-135.

42. Trujillo, D., Malkowska, D. (2018). Empirically derived connection design properties for Guadua Bamboo. Construction and Building Materials, 163, 9-20.

43. Janssen, J. J. (2000). Designing and building with bamboo. Netherlands: International Network for Bamboo and Rattan.

44. INBAR News. INBAR Pavilion Architect Mauricio Cardenas Laverde. https://www.inbar.int/inbar-pavilionarchitect-mauricio-cardenas-laverde/?from=timeline.

45. Morán, R., García, J. J. (2019). Bamboo joints with steel clamps capable of transmitting moment. Construction and Building Materials, 216, 249-260.

46. Morán, R., Muñoz, J., Silvac, H. F., Garcíad, J. J., García, J. J. (2017). A bamboo beam-column connection capable to transmit moment. 17th International Conference on Non-Conventional Materials and Technologies.

47. García, J. J., Benítez, C., Villegas, L., Morán, R. (2017). Thin steel rings as a feasible alternative to connect bamboo culms. 17th International Conference on Non-Conventional Materials and Technologies.

48. Rodríguez-Camilloni, H. (2009). Rethinking bamboo architecture as a sustainable alternative for developing countries: Juvenal Baracco and Simón Vélez. Proceedings of the Third International Congress on Construction History.

49. Paraskeva, T., Pradhan, N. P., Stoura, C. D., Dimitrakopoulos, E. G. (2019). Monotonic loading testing and characterization of new multi-full-culm bamboo to steel connections. Construction and Building Materials, 201, 473-483.

50. Liu, K. W., Frith, O. (2013). An overview of global bamboo architecture: trends and challenges. World Architecture, 12, 27-34.

51. Wang, L. (2019). Bamboo Luum Temple preaches sustainable development in Tulum. https://inhabitat.com/bamboo-luum-temple-preaches-sustainable-development-in-tulum/.

52. Kries, M., von Vegesack, A. (2000). Grow your own house: Simon Velez and bamboo architecture. Vitra Design Museum: Balingen.

53. Correal, J. F., Echeverry, J. S. (2015). Dowel-bearing strength behaviour of guadua angustifolia kunth bamboo. http://umanitoba.ca/faculties/engineering/departments/ce2p2e/alternative_village/media/16th_NOCMAT_2015 submission 40.pdf.

54. Johansen, K. W. (1949). Theory of timber connections. International Association for Bridge and Structural Engineering, 9, 249-262.

55. Morisco, R. B. (1999). Rekayasa Bambu, Nafiri Offset, Yogyakarta.

56. Awaludin, A., Andriani, V. (2014). Bolted bamboo joints reinforced with fibers. Procedia Engineering, 95, 15-21.

57. Fu, Y. G., Wang, M. Y., Ge, H. B., Li, L. (2012). Experimental study of mechanical properties of bamboo's joints under tension and compression load. Advanced Materials Research, 450, 749-755.

58. Cabanas, G. (2018). Assessing the structural response of a mortar infilled steel eyebolt bamboo connection under bending and cyclic loads (Ph.D. Thesis). University of Surrey, Guildford, the United Kingdom.

59. Inoue, M., Nakahara, M., Tanaka, K., Adachi, H., Imabayashi, M. et al. (2004). Development of connecting method for natural round bamboo. Proceeding of World Conference on Timber Engineering. 
60. Inoue, M. (2003). Development of new connecting system for timber joint using adhesive and bamboo laminated connector. Proceedings of the IAWPS, 1, 736-740.

61. Zhang, N. (2009). New construction technology of bamboo houses node (Ph.D. Thesis). Kunming University of Science and Technology, Kunming, China.

62. Bi, M. (2016). The original bamboo building of the new node structure design and construction technology (Ph.D. Thesis). Jilin Jianzhu University, Changchun, China.

63. Bacthiar, G. (2012). Compression behavior of space truss elements of Bamboo. Proceedings of 4th Indonesia Wood of Research Society Conference.

64. Ohta, M., Sawamura, Y. (2012). Development of a bamboo-tube truss member connectable by bolts. Proceedings of 4th Indonesia Wood of Research Society Conference.

65. Huang, G. Q. (2013). The experimental research and analysis on the mechanical properties of reinforced bamboo (Ph.D. Thesis). Shanghai Jiao Tong University, Shanghai, China.

66. Zhang, B. R., Liu, Z. H. (2013). Study on bamboo buildings of bamboo-wood cup joints with wooden tenonmortise joints. Journal of Jiamusi University (Natural Science Edition), 31(4), 490-495.

67. Masdar, A., Suhendro, B., Siswosukarto, S., Sulistyo, D. (2015). The study of wooden clamps for strengthening of connection on bamboo truss structure. Jurnal Teknologi, 72(5), 97-103.

68. Masdar, A., Suhendro, B., Siswosukarto, S., Sulistyo, D. (2017). Influence of bolt tightening's force to the strength of connection system of bamboo truss structure with wooden clamp. Procedia Engineering, 171, 1370-1376.

69. Masdar, A., Siswosukarto, S., Noviarti, Suryani, D. (2019). Implementation of connection system of wooden plate and wooden clamp on joint model of bamboo truss structures. International Journal of GEOMATE, 17, 15-20.

70. China Green Times. The perfect integration of science and art-"The Eye of Bamboo". http://www.greentimes.com/greentimepaper/html/2019-04/25/content 3332541.htm.

71. Lefevre, B., West, R., O’Reilly, P., Taylor, D. (2019). A new method for joining bamboo culms. Engineering Structures, 190, 1-8.

72. Matson, C. W., Sweet, K. (2016). Simplified for resilience: a parametric investigation into a bespoke joint system for bamboo. Blucher Design Proceedings, 3(1), 405-411.

73. Di Paola, F., Mercurio, A. (2019). Design and digital fabrication of a parametric joint for bamboo sustainable structures. International Conference on Applied Human Factors and Ergonomics, 180-189. 